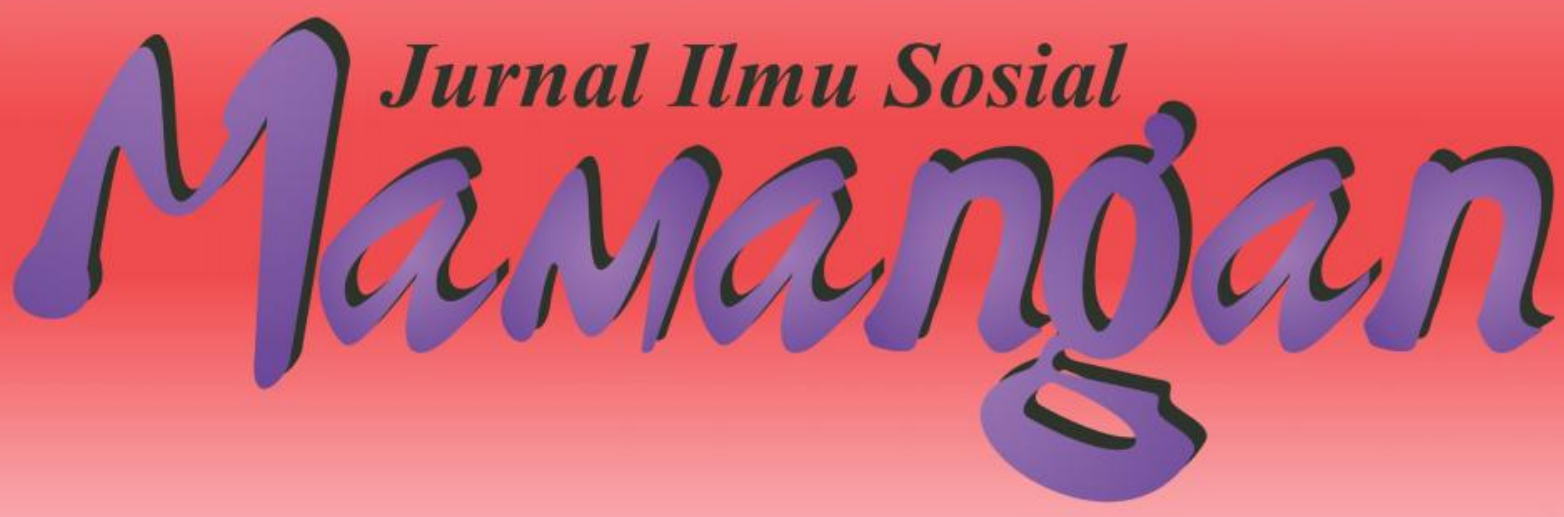

Diamika Perempuan Pedagang Makanan Di Sicincin

Elsa melia Roza, Yulkardi \& Rinel Fitlayeni

Motivasi \& Strategi Keluarga Miskin Nagari Talu, Kab. Pasaman Barat Melanjutkan Pendidikan Anak Ke Perguruan Tinggi

Cici Rahma Sari, Elvawati \& Dian Kurnia Anggreta

Dampak Sosial Ekonomi Objek Wisata The Unique Park Waterboom Di Kota Sawahlunto

Lisa Desatria, Fachrina \& Faishal Yasin

Pandangan Rumah Tangga Sasaran (RTS) Terhadap Pelaksanaan Dana Bergulir PNPM-MP Di Kelurahan Balai Gadang, Kota Padang Elparianti, ArdiAbbas \& Elvawati

Kehidupan Waria Di Jorong Mandiangin, Kecamatan Kinali, Kabupaten Pasaman Barat

Susanki \& Dian Anggraini Oktavia

Fungsi Koperasi Serba Usaha Ekonomi Desa (KSU-ED) Terhadap Masyarakat Nagari Tabek Talang Babungo, Kabupaten Solok Yenti Welia, Witrianto \& Refni Yulia 


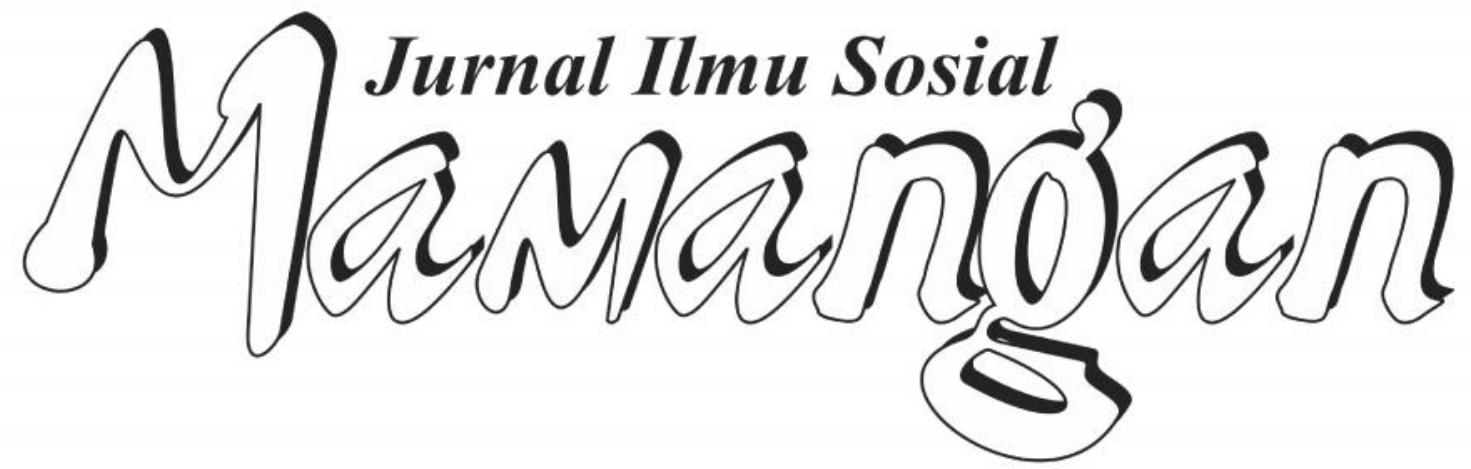




\section{Mitra Bestari}

Prof. Dr. Afrizal, MA. (FISIP, Unand Padang)

Dr. A. Latief Wiyata, M. Si. (Universitas Jember, Jember)

Prof. Dr. Badaruddin, M. Si. (FISIP, USU Medan)

Dr. Fikarwin Zuska, M. Si. (FISIP, USU Medan)

Nurus Shalihin, M. Si., Ph.D. (Fak. Ushuluddin IAIN Imam Bonjol Padang)

Dr. Semiarto A. Purwanto, M. Si. (FISIP, UI Jakarta)

Dr. Wahyu Wibowo, M. Si. (Universitas Nasional, Jakarta)

\section{Dewan Redaksi}

Dr. Zusmelia, M. Si.

Dr. Maihasni, M. Si.

Adiyalmon, S. Ag., M. Pd.

Firdaus, S. Sos., M. Si.

\section{Pemimpin Redaksi}

Firdaus, S. Sos., M. Si.

\section{Anggota Redaksi}

Dian Kurnia Anggreta, S. Sos., M. Si.

Rinel Fitlayeni, S. Sos., MA.

Surya Prahara, SH.

ISSN: 2301-8496

\section{Alamat Redaksi:}

Laboratorium Program Studi Pendidikan Sosiologi, STKIP PGRI Padang

Jl. Gunung Pangilun, Padang

Email: redaksimamangan@yahoo.com

Penerbit :

Program Studi Pendidikan Sosiologi, STKIP PGRI Padang

\section{Contac person :}

Firdaus (Hp. 085263881221/Email : daus gila@yahoo.com) 


\section{DAFTAR ISI}

Diamika Perempuan Pedagang Makanan Di Sicincin

Elsa melia Roza, Yulkardi \& Rinel Fitlayeni.

Motivasi \& Strategi Keluarga Miskin Nagari Talu, Kab. Pasaman Barat Melanjutkan Pendidikan Anak Ke Perguruan Tinggi

Cici Rahma Sari, Elvawati \& Dian Kurnia Anggreta.

Dampak Sosial Ekonomi Objek Wisata The Unique Park Waterboom Di Kota Sawahlunto

Lisa Desatria, Fachrina \& Faishal Yasin

Pandangan Rumah Tangga Sasaran (RTS) Terhadap Pelaksanaan Dana Bergulir PNPM-MP Di Kelurahan Balai Gadang, Kota Padang

Elparianti, Ardi Abbas \& Elvawati

Kehidupan Waria Di Jorong Mandiangin, Kecamatan Kinali, Kabupaten Pasaman Barat

Susanki \& Dian Anggraini Oktavia

Fungsi Koperasi Serba Usaha Ekonomi Desa (KSU-ED) Terhadap Masyarakat Nagari Tabek Talang Babungo, Kabupaten Solok 


\title{
DAMPAK SOSIAL EKONOMI OBJEK WISATA THE UNIQUE PARK WATERBOOM DI KOTA SAWAHLUNTO
}

\author{
Lisa Desatria1, Fachrina² \& Faishal Yasin ${ }^{3}$ \\ ${ }^{1 \& 3}$ Sekolah Tinggi Keguruan dan Ilmu Pendidikan (STKIP) PGRI Sumatera Barat \\ 2 Universitas Andalas
}

\begin{abstract}
Tourism development could improve people's lives, because of growth in employment, due to the opportunities new ventures. Government Sawahlunto is one area that also develop tourism for the economic growth of tourism is one of the locations Unique Park Waterboom. The purpose of this study was to describe how social and economic impacts once established waterboom Village Muaro Kalaban Silungkang District of Sawahlunto. This study used a qualitative approach and descriptive type. Data collected by observation, interview and document analysis. In-depth interviews were conducted at several informants community representatives and community leaders such as village chief Muaro Kalaban, Head of Dusun Sawah tabang, traders around. The results showed that after the establishment of The Unique Park Waterboom Muaro Kalaban social and economic impacts. Its social effects are positive impacts and negative impacts. The negative impact is imitate how to dress, way of thinking and swim behavior, religious values of society. While the positive impact that increased education and relations of good interaction. The economic impact that arises is to create jobs for the people, rising incomes, the community initiative to build shophouses, increasing public facilities and infrastructure such as roads.
\end{abstract}

\section{Keywords : Tourism, Socio-Economic Impact, Tourism Development,.}

\begin{abstract}
ABSTRAK
Pembangunan pariwisata daerah bisa meningkatkan taraf kehidupan masyarakat, karena pertumbuhan lapangan pekerjaan akibat adanya peluang usaha baru. Pemerintah Kota Sawahlunto merupakan salah satu daerah yang juga mengembangkan pariwisata untuk pertumbuhan ekonomi salah satu lokasi wisatanya adalah The Unique Park Waterboom. Tujuan penelitian ini adalah untuk mendeskripsikan bagaimana dampak sosial ekonomi setelah adanya objek wisata waterboom di Desa Muaro Kalaban Kecamatan Silungkang Kota Sawahlunto. Penelitian ini menggunakan pendekatan kualitatif dengan tipe deskriptif. Data dikumpulkan dengan observasi, wawancara mendalam dan studi dokumen. Wawancara mendalam dilakukan pada beberapa informan yaitu perwakilan masyarakat dan tokoh -tokoh masyarakat seperti Kepala Desa Muaro Kalaban, Kepala Dusun Sawah Tabang, pedagang yang di sekitar objek wisata. Hasil penelitian mengungkapkan bahwa setelah berdirinya objek wisata The Unique Park Waterboom Muaro Kalaban menimbulkan dampak sosial dan ekonomi. Dampak sosial yang ditimbulkan terbagi atas dua yaitu dampak positif dan dampak negatif. Dampak negatif yaitu meniru cara berpakaian dan prilaku berenang, nilai keagamaan masyarakat mulai luntur. Sedangkan dampak positif yaitu meningkatnya pendidikan dan terjalinnya hubungan interaksi yang baik. Dampak ekonomi yaitu terciptanya lapangan pekerjaan, meningkatnya pendapatan masyarakat, adanya inisiatif masyarakat untuk membangun ruko-ruko, dan meningkatnya sarana-prasarana umum.
\end{abstract}

Kata Kunci: Pariwisata, Dampak Sosial Ekonomi , Pmbangunan Pariwisata 


\section{PENDAHULUAN}

Menurut Budiman (Budiman 1995), pembangunan adalah kemajuan yang dicapai oleh sebuah masyarakat dibidang ekonomi. Sedangkan menurut Harun dan Elviharo (Harun 2011), pembangunan yang bergunan menuju suatu sistem sosial ekonomi yang diputuskan sebagai kehendak suatu bangsa.

Secara umum tujuan pembangunan ekonomi adalah mencapai pertumbuhan ekonomi yang tinggi, menjaga kestabilan harga, mengatasi masalah pengangguran, menjaga keseimbangan neraca pembayaran, dan pendistribusian yang lebih adil dan merata. Pembangunan ekonomi merupakan suatu proses mutlak yang dilakukan oleh satu bangsa dalam meningkatkan taraf hidup dan kesejahteraan seluruh bangsa tersebut. Indonesia yang salah satu negara yang berkembang masih mengalami ketertinggalan dibanding dengan negaranegara industri maju dalam pembangunan ekonominya yang masih mengharuskan pemerintah untuk mengambil peranan sebagai motor penggerak pembangunan ekonomi nasional.

Salah satu pembangunan ekonomi yang bisa merubah dan meningkatkan kualitas kehidupan masyarakat ke arah yang lebih baik misalnya mengembangkan sektor pariwisata. Berkembangnya sektor pariwisata masyarakat bisa menikmati keindahan alam suatu daerah yang barang kali tidak terdapat di daerahnya dan tercapai keinginan berlibur dan beristirahat setelah bekerja keras secara kontinue agar kesegaran jasmani dan rohani dapat dipulihkan kembali. Pembangunan pariwisata dapat meningkatkan taraf hidup masyarakat karena menumbuhkan lapangan pekerjaan dengan mengembangkan usaha-usaha yang mereka rencanakan (Dinas Pariwisata Sawahlunto).

Beragamnya destinasi pariwisata di Indonesia seperti Taman Mini Indonesia
Indah, Taman Impian Jaya Ancol, Kebun Binatang Ragunan, dan lain sebagainya, mempunyai daya tarik masyarakat untuk berkunjung. Provinsi Sumatera Barat juga memiliki objek wisata antara lain adalah Jam Gadang di Kota Bukittinggi, Pantai Air Manis di Kota Padang, Pantai Gondariah di Kota Pariaman, Puncak Lawang di Kabupaten Agam, Jembatan Akar di Pesisir Selatan, Danau Singkarak di Kabupaten Tanah Datar dan The Unique Park Waterboom Muaro Kalaban yang terletak di Kota Sawahlunto.

Kota Sawahlunto juga memiliki beragam tempat pariwisata, yang mana antara lain seperti: Museum Kereta Api Sawahlunto, Museum Gudang Ransum Sawahlunto, Lubang Kalam Sawahlunto, Kain Tenun Silungkang Sawahlunto, Danau Kandi Sawahlunto, Taman Satwa Kandi, The Unique Park Waterboom Muaro Kalaban. Pada saat searang ini yang menjadi primadona wisatawan di Sumatera Barat adalah objek wisata The Unique Park Waterboom Muaro Kalaban karena objek ini merupakan gebrakan baru pada tahun 2007 di dunia pariwisata Sumatera Barat. Walikota Sawahlunto Ir. H. Amran Nur mempunyai ide untuk memajukan dan meningkatkan peluang investasi di daerahnya, setelah walikota melihat potensi pemandian tersebut menjadi sebuah arena waterboom (Bakaruddin 2011).

Sebelum berdirinya waterboom tersebut dulunya hanya sebuah objek pemandian biasa yang dikenal dengan pemandian Bina Ria Air Dingin Muaro Kalaban. Namun demikian pemandian Bina Ria Air Dingin ini pengunjungnya tidak begitu ramai karena pemandian ini hanya pemandian biasa yang tidak begitu menarik untuk dikunjungi oleh masyarakat dan tidak bisa meningkatkan Pendapatan Asli Daerah (PAD) Kota Sawahlunto. Akan tetapi setelah berdirinya Waterboom, barulah meningkat pengunjung (Bakaruddin 2011). 
The Unique Park Waterboom diresmikan pada tanggal 1 Januari 2007 oleh Gubernur Sumatera Barat, Gamawan Fauzi. Gubernur langsung datang ke tempat pemandian objek wisata yang berada di Desa Muaro Kalaban Kecamatan Silungkang Kota Sawahlunto, dipinggiran jalan Lintas Sumatera. Disamping itu di sekitar objek wisata waterboom juga dilengkapi dengan area parkir yang luas, sejumlah warung dengan jenis makanan yang beraneka ragam, menjadi salah satu sumber pendapatan masyarakat yang berada di area waterboom.

Perkembangan pariwisata adalah satusatunya cara untuk memajukan tingkat ekonomi di daerah-daearah yang kurang berkembang sebagai akibat kurannya sumber-sumber daya lainnya (Pendit 2006). Untuk meningkatkan arus wisatawan kesuatu daerah atau wilayah tertentu berbagai macam pelayanan dan fasilitas yang semakin meningkat jumlah dan ragamnya. Hal ini memberikan manfaat ekonomi bagi penduduk, pengusaha, maupun pemerintah setempat. Seperti kesempatan berusaha terbuka luas, baik usaha langsung misalnya usaha restoran, ruman makan, biro pejalanan, toko sovenir, pramuwisata pusat pembelanjaan dan sebagainya (Bakaruddin 2011).

Berdasarkan oberservasi awal berdirinya The Unique Park Waterboom Muaro Kalaban tersebut diasumsikan bisa merubah kondisi sosial ekonomi masyarakat di sekitar objek wisata waterboom. Pada kenyataan saat ini terlihat banyak jenis usaha yang bermunculan di sekitar objek wisata dan tentunya akan juga berpengaruh pada tingkat ekonomi masyarakat yang membuka uasah. Pertanyaan utama pada penelitian ini adalah bagaimana dampak sosial ekonomi setelah adanya objek wisata The Unique Park Waterboom di Desa Muaro Kalaban Kota Sawahlunto. Tujuan penelitian adalah untuk mendeskripsikan bagaimana dampak sosial ekonomi setelah adanya objek wisata The Unique Park Waterboom.

\section{TINJAUAN PUSTAKA}

Menurut Lauer perubahan didefenisikan sebagai konsep inklusif yang mengacu kepada perubahan fenomena sosial di berbagai tingkat, mulai dari individu hingga tingkat dunia perubahan sosial dapat dibayangkan sebagai perubahan yang terjadi di dalam atau mencakup sistem sosial (Lauer 1993)). Lebih tepatnya, terdapat perbedaan antara keadaan sistem tertentu dalam jangka waktu yang berlainan. Perubahan sosial terjadi karena adanya perubahan dalam unsur-unsur yang mempertahankan keseimbangan masyarakat, seperti perubahan dalam unsur-unsur geografis, biologis, ekonomis atau kebudayaan (Soekanto 2012). Sektor pariwisata juga mengalami perubahan, dan masif pada kurun waktu 2 tahun belakang.

Terdapat beberapa penelitian tentang perkembangan pariwisata, diantaranya adalah Ismi Andriyani pada tahun 2012 perubahan sosial-ekonomi yang disebabkan oleh pengembangan pariwisata. Penelitian ini melihat bagaimana perkembangan wisata bahari di kepulauan sikakap tahun 20032009, bagaimana perubahan sosial ekonomi masyarakat desa sikakap setelah adanya pengembangan wisata bahari, sedangkan tujuannya untuk melihat sejauh mana dampak pembangunan pariwisata bahari mempengaruhi kondisi dan keadaan sosial ekonomi masyarakat Sikakap. Dikatakan berdampak positif karena dengan adanya wisata bahari tersebut telah mampu mengubah keadaan sosial ekonomi masyarakat jika dibandingkan sebelum adanya perkembangan wisata bahari di Kepulauan Sikakap. Dampak positif tersebut dilihat dari segi sarana prasarana, seperti sarana tranformasi, perhotelan, pasar dan fasilitas umum yang banyak mengalami perkembangan dan dampak postif lainnya dilihat dari berkurangnya angkat pengangguran (Andriyani, Hardi, and Husnita 2012). Berbeda dengan penelitian sekarang, yang mana penelitan ini melihat bagaimana dampak sosial dan ekonomi masyarakat setelah berdirinya objek wisata The Unique Park Waterboom di Kenagarian Muaro Kalaban Kecamatan Silungkang Kota Sawahlunto. Dampak sosial dilihat seperti meningkatnya pendidikan, hubungan interaksi masyarakat, masyarakat meniru cara berpakaian wisatawan yang datang ke waterboom dan nilai keagamaan masyarakat sudah mulai luntur. Sedangkan dampak ekonomi dilihat dari terbukanya lapangan pekerjan meningkatnya pendapatan masyarakat, adanya inisiatif masyarakat untuk membangun ruko dan warung, 
meningkatnya sarana dan prasarana seperi jalan yang ada di depan waterboom.

Penelitian selanjutnya dalam masalah ini Vandrio Alasca tahun 2012 dengan judul Pengaruh Objek Wisata Jembatan Akar Terhadap Perubahan Kehidupan Sosial Ekonomi Masyarakat Puluik-Puluik Kecamatan Bayang Utara Kabupaten Pesisir Selatan. Penelitian ini melihat bagaimana perkembangan jembatan akar sebelum pemetaan SK Bupati Pesisir Selatan, penelitian ini melihat bagaimana pengaruh objek wisata jembatan akar terhadap perubahan sosial, ekonomi, dan budaya masyarakat Puluik-Puluik. Pengembangan objek wisata Jembatan Akar telah meningkatkan populasi pengunjung yang mengunjungi jembatan akar. Peningkatan ini ada setelah pengembangan dan pembangunan sarana dan prasarana serta infrastruktur yang mendukung jembatan akar serta menambah daya tarik pengunjung. Perkembangan tersebut berpengaruh terhadap sosial ekonomi masyarakat puluikpuluik dengan adanya objek wisata jembatan akar, yang dari awalnya berprofesi sebagai petani, selanjutnya bisa menjadi pedagang yang saat mendapatkan kesejahteraan ekonomi masyarakat setempat (Alasca 2012). Berdasarkan beberapa penelitian sebelumnya dilihat bahwa beberapa pembangunan pariwisata di Sumatera Barat menunjukkan pengaruh sosial yang besar. Penelitian ini juga ingin melihat apa pengaruh The Unique Park Waterboom terhadap sosial ekonomi masyarakat sekitar.

\section{METODE}

Penelitian ini menggunakan pendekatan kualitatif, dengan informan sebanyak 15 orang, diantaranya pedagang yang berjualan di area parkir waterboom, pedagang yang berjualan di sekitar objek wisata waterboom, bapak Kepala Desa Muaro Kalaban, bapak Dusun Sawah Tambang dan anggota masyarakat yang ada di sekitar objek wisata waterboom Muaro Kalaban Kecamatan Silungkang Kota Sawahlunto. Penelitian dilaksanakan selama tiga bulan yaitu bulan Juli 2013 hingga Oktober 2013.

\section{DAMPAK SOSIAL OBJEK WISATA WATERBOOM MUARO KALABAN.}

Pesatnya pembangunan berdampak pada perubahan sosial budaya yang terjadi didalam masyarakat. Perubahan tersebut diantaranya perubahan dari masyarakat tertutup menjadi masyarakat yang lebih terbuka, dari nilai-nilai yang bersifat homogen menuju pluralisme nilai dan norma sosial. Menurut Paul B. Horton (Horton 2010) Kebudayaan adalah komplek keseluruhan dari pengetahuan, keyakinan, kesenian, moral, hukum, adat istiadat dan semua kemampuan dan kebiasaan yang lain yang diperoleh oleh seseorang sebagai anggota masyarakat, bila dinyatakan secara sederhana kebudayaan adalah segala sesuatu yang dipelajari dan dialami bersama secara sosial oleh para anggota masyarakat. Seseorang menerima kebudayaan sebagai bagian dari warisan sosial, dan pada gilirannya, bisa membentuk kebudayaan kembali dan mengenalkan perubahanperubahan yang kemudian menjadi bagian dari warisan generasi yang berikutnya. akibat proses pembangunan itu sendiri.

Menurut Pizam dan Milman (Pitana 2009) klasifikasi dampak sosial budaya adalah:

1. Dampak terhadap aspek demografi (jumlah penduduk, umur, perubahan piramida kependudukan).

2. Dampak terhadap mata pencarian (perubahan pekerjaan, distribusi pekerjaan).

3. Dampak terhadap aspek budaya (tradisi,keagamaan,bahasa).

4. Dampak terhadap transformasi norma (nilai, norma, peranan seks).

5. Dampak terhadap modifikasi pola konsumsi (infrastruktur, komuditas).

6. Dampak terhadap lingkungan (populasi, kemacetan lalu lintas).

Penelitian ini hanya membatasi pada dampak sosial seperti dampak terhadap transformasi norma yaitu adanya perubahan norma prilaku masyarakat sebelum dan sesudah adanya waterboom dilihat dari cara berpakaian masyarakat di daerah waterboom ketika bepergian.

\section{Cara Berpakaian dan Prilaku Berenang}

Berdasarkan hasil wawancara di lapangan dengan masyarakat di sekitar objek wisata waterboom Muaro Kalaban mengenai dampak sosial sebelum dan setelah berdirinya objek wisata waterboom. Berikut hasil wawancara dengan salah satu masyarakat di sekitar 
objek wisata waterboom. Wawancara dilakukan dengan Ibu Niar (46 tahun) sebagai berikut:

"semenjak saya tinggal di sekitar objek wisata waterboom, saya melihat setelah adanya waterboom masyarakat mulai tidak memperhatikan cara berpakian keluar rumah, sekarang banyak masyarakat Muaro Kalaban terutama para remaja yang memakai celana pendek, dan baju yang ketat ketika bepergian. Tetapi masyarakat yang melihat para remaja tersebut tidak mau tau atas apa yang mereka lakukan. Masyarakat hanya melihat dan tidak pernah menegurnya" (wawancara 24 Agustus 2013)"

$$
\text { Menurut salah satu }
$$

masyarakat yang tinggal di sekitar objek wisata waterboom yaitu Ibu Niar terlihat bahwa tidak ada rasa malu masyarakat khususnya para remaja berpakaian yang kurang sopan, seperti memakai celana pendek dan baju ketat. Para remaja tidak memikirkan kalau mereka akan dikucilkan oleh masyarakat lain karena para remaja telah melanggar norma khususnya norma kesopanan. Seperti pendapat Maryati (Maryati 2006) norma kesopanan adalah norma yang berpangkal dari aturan tingkah laku yang berlaku di masyarakat seperti cara berpakaian,cara bersikap dalam pergauan, dan berbicara. Norma ini bersifat relatif. Maksudnya penerapannya berbeda menentukan kategori pantas dalam berbusana antara tempat yang satu dengan yang lain terkadang berbeda. Tetapi para remaja tidak peduli dengan apa yang dia lakukan. Berbeda dengan masa duhulu para remaja merasa malu ketika berpakaian kurang sopan.

Selain Ibu Niar, Ibu Tanti juga mengatakan hal demikian, berikut wawancara dengan Ibu Tanti (30 tahun):
"memang setelah adanya
waterboom masyarakat sudah
merubah penampilannya dari tertutup menjadi terbuka. Dulunya masyarakat keluar rumah tidak berani memakai celana pendek dan baju ketat, tetapi sekarang setelah

adanya waterboom masyarakat sudah merubah penampilannya lebih terbuka" (wawancara 22 Agustus 2013)

Perubahan yang dilakukan oleh masyarakat Muaro Kalaban disebabkan oleh faktor masyarakat sering melihat wisatawan yang datang ke objek wisata waterboom yang dengan cara berpakaian kurang sopan. Akibatnya masyarakat di sekitar objek wisata waterboom meniru cara tersebut. Dalam kategori ini kejahatan sebagai masalah sosial justru diakibatkan oleh datangnya wisatawan dengan prilaku menyimpang (Pitana 2009).

Wawancara dengan Yuniar mengungkapkan pada saat mereka berenang, para remaja memperlihatkan kelakuan yang tidak wajar seperti saling bersentuhan dengan lawan jenis, yang mana kadang-kadang disengaja oleh remaja tersebut terutama remaja lakilaki. Tidak hanya itu mereka yang berseluncuran antara laki-laki dengan perempuan bersamaan saling senggol menyenggol satu sama lain. Kelakuan para remaja tersebut sering ditegur oleh karyawan waterboom. Karena tugas karyawan adalah menjaga keamanan dan ketertiban dalam waterboom, tetapi para wisatawan terutama para remaja tidak menghiraukannya.

\section{Nilai Keagamaan Sudah Mulai Luntur}

Adanya perbedaan penerapan nilai keagamaan masyarakat saat ini dengan masa dahulu. Masa dahulu masyarakat yang ada di sekitar waterboom seharihari mereka diisi dengan hal-hal yang positif seperti gotong royong satu kali dalam seminggu dan sholat berjema'ah di mushalla, tidak seperti sekarang setelah adanya waterboom. Hal postif seperti dulu tidak semua masyarakat yang melakukannya begitu juga pedagang yang berjualan di area waterboom, ketika waktu sholat datang banyak yang tidak melaksanakan sholat. Padahal di waterboom tersebut disediakan mushalla tempat beribadah pengunjung dan pedagang yang ada di area waterboom. Di saat waktu sholat datang kebanyakan pedagang hanya 
sibuk dengan pekerjaannya masingmasing seperti sibuk melayani pembeli.

\section{Meningkatkan Pendidikan}

Pendidikan masyarakat yang ada di sekitar waterboom masih banyak yang tidak mengutamakan pendidikan, padahal pendidikan adalah kebutuhan dasar bagi manusia, dari pendidikan tersebut bisa menambah pengentahuan dan meningkatkan keterampilan dan tenaga kerja. Pendidikan adalah usaha sadar dan terencana untuk mewujudkan suasana belajar dan proses pembelajaran agar peserta didik secara aktif mengembangkan potensi dirinya untuk memiliki kekuatan spiritual keagamaan, pengendalian diri, kepribadian, kecerdasan, akhlak mulia, serta keterampilan yang diperlukan dirinya dalam masyarakat. Tetapi kalau dibandingkan dengan sekarang sudah ada peningkatan dari sebelum berdirinya waterboom, yang mana duhulu masyarakat hanya menyekolahkan anaknya sampai Sekolah Menengah Pertama (SMP) dan ada yang berhenti ketika duduk di bangku SMA. Tetapi jika dilihat saat ini masyarakat sudah banyak yang melanjutkan pendidikan anaknya keperguruan tinggi. Itu disebabkan karena pendapatan masyarakat meningkat karena adanya objek wisata waterboom.

Menurut ibu Jurmiati dan ibu Linda sekarang masyarakat Muaro Kalaban sudah mulai peduli dengan pendidikan anaknya. Sudah banyak anak-anak melanjutkan pendidikan ke Perguruan Tinggi dan sakarang ini jarang ditemukan lagi anak yang putus sekolah. Seperti anak dari ibu Jurmiati yaitu Viona dan Rici, sekarang Viona dan Rici sudah kuliah di Universitas Andalas yang mana sekarang Viona sudah tingkat akhir sedangkan Rici sudah memasuki tingkat dua. Menurut ibu Jurmiati pendidikan anak harus diutamakan dan menurut ibu Jurmiati pendapatan yang ibu dapat semata-mata hanya untuk biaya pendidikan anaknya. Begitu juga menurut ibu Lidia, sekarang anak ibu Lidia juga sudah berkuliah di perguruan tinggi swasta Bukittinggi.

\section{Terjadinya Hubungan Interaksi Yang Baik.}

Berdasarkan wawancara dengan beberapa pedagang di area parkir objek wisata waterboom, diketahui ada dampak sosial seperti persaingan antara sesama pedagang yang jenis jualannya sama di area tersebut. Tetapi persaingan yang terjadi masih pada persaingan sehat. Pedagang tidak pernah memperlihatkan rasa iri hatinya kepada pedagang lain, bahkan pedagang menunjukkan bahwa ada kerjasama antara pedagang yaitu sama-sama menolong ketika pedagang lain meminta pertolongan seperti mengangkat barang yang sudah terlalu berat. Interaksi antara pedagang terlihat baik, sebelum dan sesudah berdirinya waterboom. Seperti menurut Maryati (Maryati 2006) interaksi sosial adalah hubungan antara individu dengan individu, antara individu dengan kelompok dan antara kelompok dengan kelompok. Bahkan jika dilihat setelah berdirinya waterboom hubungan sosial antara pedagang dengan pedagang, pedagang dengan masyarakat sudah jauh lebih akrab antara sesama pedagang.

Penyataan diatas memperkuat dampak sosial keberadaan objek wisata waterboom ini mempunyai dua dampak yaitu dampak positif dan dampak negatif. Terlihat bahwa hasil wawancara ibu Asnibar membincangkan bahwa adanya waterboom berdampak positif hubungan interaksi antara sesama pedagang, pedagang dengan masyarakat, dan pedagang dengan pengunjung terlihat sangat baik, walupun disana dijelaskan ada persaingan tetapi persaingan antara sesama pedagang tersebut persaingan sehat. Sedangkan dengan ibu Niar dan ibu Tanti berdampakkan negatif dilihat dari cara berpakaian pengunjung yang tidak sopan.

\section{DAMPAK EKONOMI OBJEK WISATA WATERBOOM MUARO KALABAN}

\section{Terciptanya Lapangan Pekerjaan}

Berdirinya objek wisata waterboom bisa membuka lapangan pekerjaan bagi masyarakat di sekitar seperti karyawan waterboom dan sebagian masyarakat juga menjual cenderamata dan makanan di area waterboom. Banyak masyarakat 
di area waterboom yang menjadi karyawan khususnya pemuda dan pemudi yang ada di sekitar waterboom, yang mana dulunya sebelum adanya waterboom pemuda dan pemudi tidak memiliki pekerjaan dan banyak yang menjadi pengangguran. Setelah dibangunnya waterboom Muaro Kalaban ini lapangan pekerjaan terbuka bagi pemuda dan pemudi yang ada di Desa Muaro Kalaban seperti menjadi karyawan waterboom.

Menurut bapak Kepala Desa Muaro Kalaban, setelah adanya objek wisata waterboom Muaro Kalaban terlihat bahwa terjadinya peningkatan objek wisata waterboom Muaro Kalaban terlihat bahwa terjadinya peningkatan pendapatan masyarakata Muaro Kalaban terutama masyarakat yang ada di sekitar objek wisata waterboom. Banyak masyarakat setelah adanya waterboom berinisiatif untuk berjualan di sekitar waterboom dengan membangun rukoruko dan warung warung di sekitar objek wisata waterboom dan juga bisa menciptakan lapangan pekerjaan untuk masyarakat sebagai karyawan waterboom. Pada tabel 1 dapat dilihat jumlah karyawan di serap oleh waterboom Muaro Kalaban dan pedagang yang berdagang.

Tabel 1

Jenis Lapangan Pekerjaan \& Dagangan di Sekitar Objek Wisata Waterboom Muaro Kalaban Tahun 2013

\begin{tabular}{|c|l|c|c|c|}
\hline \multirow{2}{*}{ No } & $\begin{array}{l}\text { Jenis Lapangan } \\
\text { Pekerjaan dan } \\
\text { Jenis Dagangan }\end{array}$ & Jumlah & $\begin{array}{c}\text { Asli } \\
\text { Muaro } \\
\text { Kalaban }\end{array}$ & $\begin{array}{c}\text { Penda } \\
\text { tang }\end{array}$ \\
\hline 1 & $\begin{array}{l}\text { Karyawan } \\
\text { Waterboom }\end{array}$ & 26 & 24 & 2 \\
\hline 2 & Pedagang & & & \\
\hline & a. Rumah makan & 4 & 4 & 0 \\
\hline & b. Toko pakaian & 4 & 4 & 0 \\
\hline & $\begin{array}{l}\text { c. Makanan dan } \\
\text { minuman }\end{array}$ & 7 & 7 & 0 \\
\hline & d. Kafe & 1 & 1 & 0 \\
\hline & e.grosiran & 1 & 1 & 0 \\
\hline
\end{tabular}

Sumber; Data Primer tahun 2013
Dari tabel diatas terlihat bahwa jumlah karyawan waterboom sebanyak 26 orang yang diantaranya 24 masyarakat asli muaro kalaban dan 2 orang lagi masyarakat pedatang. Dan jenis dagangan masyarakat di sekitar waterboom terbagi atas 5 jenis yaitu rumah makan, toko pakaian, makanan dan minuman, kafe dan grosiran.

\section{Meningkatnya Pendapatan Masyarakat.}

Secara umum pendapatan masyarakat di sekitar waterboom muaro kalaban menunjukkan adanya peningkatan. Berdasarkan kasus informan ibu Linda di atas, menjelaskan bahwa adanya waterboom pendapatan ibu Linda meningkat, terlihat dari pendapatan tersebut ibu Linda bisa membiayai pendidikan anaknya. Anak ibu Linda ada 4 orang yang mana anak sulung dari ibu Linda sekarang sedang kuliah di perguruan tinggi Swasta Bukittinggi, yakni Lidia, anak kedua ibu Linda bernama Alif sekarang dia sekolah di Sekolah Menengah Atas (SMA), dan dua orang lagi masih Sekolah Dasar (SD). Pendatapan itu gunanya untuk membiayai semua kebutuhan anaknya dalam menajalankan pendidikan. Biaya pendidikan meliputi biaya langsung dan biaya tidak langsung. Biaya langsung terdiri atas biaya-biaya yang dikeluarkan untuk keperluan pelaksanaan pengajaran dan kegiatan belajar siswa berupa pembelian alat-alat pelajaran, sarana belajar, biaya transportasi, gaji guru baik yang dikeluarkan oleh pemerintah, orang tua maupun siswa sendiri. Sedangkan biaya tidak langsung berupa keuntungan yang hilang dalam bentuk biaya kesempatang yang hilang yang dikorbankan oleh siswa selama belajar. Selebihnya pendapatan tersebut digunakan untuk perlengkapan bengkel yang di kelola oleh suami ibu Linda sendiri. 
Tabel 2

Jenis Dagangan Masyarakat di Area Objek Wisata Muaro Kalaban tahun 2013

\begin{tabular}{|c|l|c|c|c|}
\hline \multirow{2}{*}{ No } & \multirow{2}{*}{ Jenis dagangan } & \multirow{2}{*}{ Jumlah } & $\begin{array}{c}\text { Asli } \\
\text { Muaro } \\
\text { Kalaban }\end{array}$ & $\begin{array}{c}\text { Penda } \\
\text { tang }\end{array}$ \\
\hline 1 & Pakaian & 9 & 7 & 0 \\
\hline 2 & Makanan/minuman & 7 & 9 & 0 \\
\hline 3 & Mainan anak-anak & 2 & 2 & 0 \\
\hline 4 & Pelampung & 5 & 5 & 0 \\
\hline
\end{tabular}

Sumber; Data Primer tahun 2013

Sebelum adanya waterboom dulu ibu Gustina bekerja sebagai staf honorer di Kantor Camat Silingkang, ibu Gustina rela meninggalkan pekerjaannya tersebut demi berjualan di area waterbooom dengan pedapatan ibu Gustina sebagai honorer hanya Rp. 800.000/bulan, sedangkan sekarang pendapatang ibu Gustina sudah mebih meningkat sebesar Rp. 3.000.000/bulan. Pendapatang tersebut digunakan untuk memenuhi kebutuhan sehari-hari keluarga dan untuk biaya pendidikan anaknya selebihnya pendapatan tersebut digunakan dan untuk biaya pendidikan anaknya selebihnya pendapatan tersebut digunakan untuk membeli kendaraaan mobil bekas dan sepeda motor. Mobil tersebut kemudian digunakan oleh suaminya untuk bekerja di tambang pasir.

Tabel 3

Pendapatan Masyarakat Sebelum \& Sesudah Adanya Waterboom

\begin{tabular}{|r|l|r|r|}
\hline & \multirow{2}{*}{ Nama } & \multicolumn{2}{|c|}{ Pendapatan/Bulan } \\
\cline { 3 - 5 } No & Pedagang & \multicolumn{1}{|c|}{ Sebelum } & \multicolumn{1}{c|}{ Sesudah } \\
\hline 1 & Aprimizul & Rp. 100.000 & Rp. 2.500 .000 \\
\hline 2 & Gustina & Rp 800.000 & Rp. 3.000 .000 \\
\hline 3 & Anti & Rp 100.000 & Rp. 2.800 .000 \\
\hline 4 & Linda & Rp. 1.800 .000 & Rp. 3.000 .000 \\
\hline 5 & Asnibar & Rp. 1.200 .000 & Rp. 3.200 .000 \\
\hline 6 & Emi & Rp. 100.000 & Rp. 200.000 \\
\hline 7 & Jurmiati & Rp. 1.500 .000 & Rp. 3.000 .000 \\
\hline 8 & Nuraini & Rp. 750.000 & Rp. 1.200 .000 \\
\hline 9 & Putri & Rp. 800.000 & Rp. 1.250 .000 \\
\hline 10 & Yuliar & Rp. 1.200 .000 & Rp. 200.000 \\
\hline 11 & Dahnil & Rp. 900.000 & Rp. 2.000 .000 \\
\hline
\end{tabular}

Sumber; Data Primer tahun 2013
Dari tabel 3 terlihat bahwa perbandingan pendapatan masyarakat antara sebelum dan sesudah berdirinya waterboom sangatlah meningkat. Dari pendapatan tersebut masyarakat menggunakan untuk kebutuhan seharihari dan untuk biaya pendidikan anak dan sisanya lagi bisa membeli perabotan rumah tangga dan kendaraan.

\section{Inisiatif Membangun Ruko-Ruko}

Menurut Kepala Dusun Sawah Tambang, Semenjak adanya waterboom bapak ini melihat ada peningkatan pendapatan masyarakat Muaro Kalaban terutama di sekitar objek wisata waterboom. Peningkatan tersebut berupa banyaknya berdiri bangunan seperti ruko-ruko di sepanjang jalan tepatnya di sekitar objek wisata waterboom. Itu disebabkan karena dibangunnya objek wisata waterboom, yang mana dulunya tidak ada inisiatif masyarakat untuk mendirikan bangunan tersebut.

Karena melihat banyaknya pengunjung yang datang ke waterboom maka banyak masyarakat yang berinisiatif untuk mendirikan bangunnan seperti rumah makan, toko pakaian, dan menjual makanan dan minuman. Peningkatan tersebut juga dirasakan oleh bapak kepala Dusun Sawah Tambang yang mana bapak ini salah satu pedagang yang berjualan di area objek wisata waterboom. Sebelumnya adanya waterboom, bapak ini hanya mendapatkan pengasilan sebagai kepada dusun saja yang pendapatannya hanya Rp.1.000.000/bulan tetapi setelah berjualan di area waterboom penghasilan bapak dusun ini sudah bertambah menjadi Rp2.500.000/bulan. Pendapatan tersebut digunakan untuk kebutuhan sehari-hari keluarga dan biaya pendidikan anaknya.

\section{Meningkatnya Sarana dan Prasarana Seperti Jalan.}

Menurut bapak Dahnil dan bapak Miko, bahwa sarana dan prasarana jalan Lintas Sumatera yang ada di waterboom dulunya terlihat sempit dan jalannya 
banyak yang berlobang. Setelah adanya waterboom jalan sudah diperbaiki dan diperbesar agar pengunjung lebih leluasa untuk memarkirkan kendaraannya, tetapi pada saat lebaran dan tahun baru jalan lintas ini mengalami kemacetan karena terlalu banyak pengunjung yang datang dan pengguna jalan raya yang begitu ramai melalui jalan Lintas Sumatera. Dari pernyataan di atas dapat memperkuat bahwa dengan adanya objek wisata waterboom memberikan dampak postif kepada masyarakat muaro kalaban. Dampak positif yang biasanya langsung dan segera dapat dirasakan adalah dalam segi keuntungan ekonomi, sebagaimana telah digariskan dalam Undang-Undang Tentang Kepariwisataan No.9 Tahun 2009 yaitu salah satu tujuan penyelenggaraan kepariwisataan pendapatan daerah dalam rangka meningkatkan kesejahteraan dan kemakmuran rakyat, juga memperluas dan meratakan kesempatan berusaha dan lapangan kerja serta mendrong pembangunan daerah. Sedangkan menurut Adji (Wahyu 2007) tujuan pembangunan nasional adalah mewujudkan masyarakat adil dan makmur, yang merata material dan spiritual berdasarkan pancasila dan UUD 1945 dalam wadah Negara Kesatuan Republik Indonesia yang merdeka, berdaulat bersatu dan berkedaulatan rakyat dalam suasana perikehidupan bangsa yang aman, tentram, tertib dan dinamis dalam lingkungan pergaulan dunia yang merdeka, bersahabat, tertib dan damai.

Pembangunan pariwisata selain menimbulkan dampak ekonomi juga menimbulkan dampak sosial terhadap masyarakat yang ada di sekitar pembangunan tersebut. Dampak sosial yang terlihat seperti timbulnya penyimpangan-penyimpangan yang diakibatkan oleh budaya lain, seperti cara berpakaian, penggunaan obat terlarang, arak-arakan motor dan sebagainnya. Akibatnya masyarakat di sekitar pariwisata meniru penyimpangan tersebut. Setelah itu masyarakat yang ada di sekitar pariwisata merubah cara kehidupanya. Perubahan sosial bukanlah sebuah proses yang terjadi dengan sendirinya.

Menurut Lauer perubahan didefenisikan sebagai konsep inklusif yang mengacu kepada perubahan fenomena sosial di berbagai tingkat, mulai dari individu hingga tingkat dunia. Perubahan sosial dapat dibayangkan sebagai perubahan yang terjadi di dalam atau mencakup sistem sosial (Lauer 1993). Dengan demikian pembangunan dentinasi wisata the unique park waterboom nyata telah membuat perubahan signifikan di masayarakat Kota Sawahlunto terutapa di sekitar waterboom.

\section{KESIMPULAN}

Berdasarkan hasil penelitian ini dapat disimpulkan bahwa keberadaan objek wisata the unique park waterboom Muaro Kalaban memberikan dampak sosial ekonomi terhadap masyarakat muaro kalaban khususnya masyarakat yang tinggal di sekitar objek wisata waterboom. Dampak sosialnya adalah dapat meningkatkan pendidikan masyarakat muaro kalaban setelah adanya waterboom. Sedangkan dari segi ekonominya terciptanya lapangan pekerjaan bagi masyarakat yang ada di muaro kalaban khususnya masyarakat yang tinggal di sekitar objek wisata waterboom. Seperti menjadi karyawan waterboom dan berdagang di area maupun di sekitar objek wisata waterboom.

\section{DAFTAR PUSTAKA}

Alasca, Vandrio. 2012. "Pengaruh Objek Wisata Jembatan Akar Terhadap Perubahan Kehidupan Sosial Ekonomi Masyarakat Puluik Puluik Kecamatan Bayang Utara Kabupaten Pesisir Selatan Tahun 2002-2011." STKIP PGRI Sumatera Barat.

Andriyani, Ismi, Etmi Hardi, and Liza Husnita. 2012. "Perubahan Sosial Ekonomi Masyarakat Pasca Pengembangan Wisata Bahari Di Kepualuan Sikakap, Kabupaten Mentawai." Jurnal Ilmu Sosial Mamangan 1(2):95-101.

Bakaruddin. 2011. Perkembangan Dan Permasalahan Kepariwisataan. Padang: UNP Press.

Budiman, Arif. 1995. Teori Pembangunan 
Dunia Ke Tiga. Jakarta: PT Gramedia Pustaka Utama.

Harun, Rochajat dan Elviharo Ardianto. 2011. Komunikasi Pembangunan Perubahan Sosial. Jakarta: PT Raja Grafindo Persada.

Horton, Poul B. 2010. Sosiologi. Jakarta: PT Gelora Aksara Pratama.

Lauer, Robert. 1993. Perspektif Tentang Perubahan Sosial. Jakarta: PT Rineka Cipta.

Maryati, Kun dan Juju Suryawati. 2006. Sosiologi Untuk SMA/MA Kelas X.
Jakarta: PT Gelora Aksara Pratama.

Pendit, Nyoman S. 2006. Ilmu Pariwisata Sebuah Pengantar Perdana. Yogyakarta: PT Pradnya Paramita.

Pitana, I.Gede. 2009. Pengantar Ilmu Pariwisata. Yogyakarta: CV. Andi Offset. Soekanto, Soerjono. 2012. Sosiologi Suatu Pengantar. Jakarta: PT Raja Grafindo Persada.

Wahyu, Adji. 2007. Ekonomi Untuk SMA Kelas $X I$. Jakarta: Erlangga Gelora Aksara Pratama. 
